ISSN : 2598-0521

\title{
KONTRIBUSI KERAJINAN TIRAI TERHADAP PENDAPATAN DAN KONSUMSI KELUARGA PETANI DI DESA RANTAU DURIAN I KECAMATAN LEMPUING JAYA OGAN KOMERING ILIR
}

\author{
AISAH \\ STIPER Belitang, Jl. Kampus Pertanian No.03 Belitang. OKU Timur. Sum-Sel Telp (0735) \\ 4531056 \\ Agribisnis, STIPER Belitang, OKU Timur \\ Email : aisahputbel@gmail.com
}

\begin{abstract}
Rantau Durian I Village also has the potential for plant development in both the food crop sector and plantation crops, most of the Rantau Durian I Village area is production land or rice fields. When viewed from the irrigation point of view, rice fields are rainfed which only produce once a year, this is the reason why some of the rice fields in the village have changed their function as rubber plantations which are considered by the community to be more profitable. However, the main problem of rubber plants at this time is low rubber production and the raw materials produced are of low quality, so the price received by farmers is relatively low. This condition makes the people in the village have household activities that can support their economy after returning from tapping rubber for approximately three to four hours, so that the remaining time can be used for making curtains.

The research objectives are: 1). This is to determine the price margin for curtain marketing at the village level of Rantau Durian I, Lempuing Jaya District, OKI. 2). This is to find out how much the curtain income will be on the income and consumption of farm families from the point of view of marketing time during the months of the big day (Eid, New Year). The results show that the marketing margins on retail and wholesales are different. Where retail sales or farmers sell directly to consumers is IDR 18,000 . Whereas farmers sell to large parties with a large volume of Rp. 15,000, so the marketing margin is Rp. 3,000. The contribution of curtain crafts to the income of farmer families in Rantau Durian I Village was 24\%. Meanwhile, the contribution of curtain to the consumption of farmer families in Rantau Durian I Village is $40 \%$.
\end{abstract}

Keywords: Curtain craft, Marketing Margin, Contribution 


\section{PENDAhuluan}

\section{A. Latar Belakang}

Perkebunan kelapa sawit di Sumatera Selatan tersebar di beberapa kabupaten dan kota. Salah satunya adalah di Kabupaten Ogan Komering Ilir. Luas perkebunan kelapa sawit di Kabupaten Ogan Komering Ilir mencapai 137.992,97 ha. Menempati posisi ke dua setelah Kabupaten Musi Banyu Asin yang mempunyai luas perkebunan 239.311,65 ha. Desa Rantau Durian I merupakan desa yang memiliki letak strategis, dimana desa ini terletak tidak jauh bahkan tepat bersebelahan dengan perkebunan kelapa sawit milik PT. Tania Selatan yang memberikan banyak manfaat bagi masyarakat di Desa Rantau Durian khususnya. Manfaat yang diperoleh seperti pekerjaan dan juga penghasilan tambahan bagi para pencari pelepah sawit yang nantinya akan dijual kepada pengusaha tirai. Selain itu Desa Rantau Durian I juga memiliki potensi pengembangan tanaman baik di sector tanaman pangan maupun tanaman perkebunan. Sebagian besar wilayah Desa Rantau Durian I merupakan lahan produksi atau daerah persawahan. Bila dilihat dari sisi pengairan sawah merupakan sawah tadah hujan yang hanya berproduksi satu kali dalam setahun, hal ini yang menjadi penyebab beberapa sawah yang ada di desa tersebut telah beralih fungsi sebagai lahan perkebunan tanaman karet yang dinilai oleh masyarakat lebih menguntungkan.

Peneliti sebelumnya Bantu Triyono tahun 2014, Kontribusi Pengrajin Tikar Mendong terhadap Pendapatan Masyarakat Kabupaten OKU Timur Provinsi Sumatera Selatan. Berdasarkan hasil penelitian menyatakan bahwa persentase kontribusi pendapatan usaha pembuatan tikar mending terhadap total pendapatan keluarga rata-rata adalah sebesar 40 \% ( Rp 773.567,-/bulan ). Sedangkan persentase pendapatan usaha pembuatan tikar mending terhadap Kebutuhan Hidup Layak ( KHL ) Kabupaten OKU Timur sebesar Rp 1.594.478,-/bulan adalah $80 \%$.

Masyarakat Rantau Durian I mayoritas mempunyai mata pencaharian pokok sebagai petani karet. Tetapi permasalahan utama tanaman karet saat ini adalah produksi karet yang rendah dan bahan baku yang dihsilkan mutunya juga masih rendah sehingga harga yang diterima petani relative rendah. Kondisi inilah yang membuat masyarakat di desa tersebut mempunyai kegiatanrumah tangga yang dapat menunjang perekonomian mereka setelah pulang dari menyadap karet karena waktu yang digunakan untuk menyadap karet kurang lebih tiga sampai empat jam, sehingga sisa waktu dapat digunakan untuk membuat tirai. Tirai mempunyai beberapa fungsi setelah sampai ke tangan konsumen diantaranya sebagai tikar, sebagai tirai untuk penghalang sinar matahari langsung, ada juga menggunakan tirai sebagai plagfon rumah dan dinding rumah. Dengan adanya kegiatan rumah tangga ini diharapkan memberikan kontribusi terhadap pendapatan keluarga petani di desa tersebut.

\section{Rumusan Masalah}

Dari uaraian latar belakang di atas maka rumusan masalah yang dapat diambil adalah

1. Bagaimana margin harga pada pemasaran tirai di tingkat Desa Rantau Durian I Kecamatan Lempuing Jaya OKI ?

2. Berapa besar pendapatan dari kerajinan tirai dan pendapatan untuk keluarga petani di Desa Rantau Durian I Kecamatan Lempuing OKI ?

\section{B. Tujuan Penelitian}

Tujuan penelitian ini adalah :

1. Untuk mengetahui margin harga pada pemasaran tirai ditingkat Desa Rantau Durian I Kecamatan Lempuing OKI.

2. Untuk mengetahui berapa besar pendapatan tirai terhadap pendapatan 
dan konsumsi keluarga petani jika dilihat dari sudut pandang waktu pemasaran di bulan-bulan biasa dibandingkan dengan bulan-bulan hari besar ( lebaran, tahun baru ).

\section{Hipotesis}

1. Bahwa terdapat margin pemasaran yang berbeda pada penjualan tirai eceran dan partai besar di Desa Rantau Durian I Kecamatan Lempuing OKI.

2. Bahwa kerajinan tirai mempunyai kontribusi terhadap pendapatan total keluarga dan pemenuhan konsumsi keluarga petani di Desa Rantau Durian I Kecamatan Lempuing OKI.

\section{METODE PELAKSANAAN}

A. Tempat dan Waktu

Penelitian ini telah dilaksanakan di Desa Rantau Duran I Kecamatan Lempuing Jaya Kabupaten Ogan Komering Ilir. Penentuan tempat dilakukan secara sengaja (purposive). Dengan pertimbangan di desa tersebut mayoritas penduduknya adalah pembuat kerajinan tirai.

B. Metode Penelitian dan Penarikan Contoh

Metode penelitian yang digunakan adalah metode survey. Metode survey adalah penyelidikan yang diadakan untuk memperoleh fakta-fakta dari gejala-gejala yang ada dan mencari keterangan-keterangan secara factual, baik tentang institusi social, ekonomi arau politik dari suatu kelompok atau suatu daerah.

Metode penarikan contoh dilakukan secara acak sederhana (simple random sampling) dengan jumlah sampel 39 orang pengusaha kerajinan tirai. Pengambilan sampel ini didasarkan pada data lapangan yang populasinya berjumlah 309 orang pembuat kerajinan tirai dengan menggunakan tingkat error sebesar $15 \%$.

$$
\mathrm{n}=\overline{1+\mathrm{Ne}^{2}}
$$

Keterangan :

$\mathrm{n}=$ Sampel $\quad \mathrm{N}=$ Populasi $\mathrm{e}=$ tingkat error $(0,15)$.

C. Metode Pengumpulan dan Pengolahan Data

Data yang dikumpulkan dalam penelitian ini adalah data primer dan data skunder. Data primer diperoleh dari observasi dan wawancara langsung dengan pihakpihak yang menjadi objek penelitian dengan menggunakan quisioner atau data pertanyaan. Sedangkan data skunder diperoleh dari perpustakaan dan instansi/lembaga-lembaga terkait yang berhubungan dengan penelitian ini.

Metode pengolahan data dilakukan secara tabulasi dandilanjutkan dengan pendeskripsian dari data primer dan skunder yang diperoleh secara langsung di daerah penelitian.

1. Untuk mengetahui marjin harga pada pemasaran tirai ditingkat Desa Rantau Durian I Kecamatan Lempuing Jaya dilakukan observasi dan wawancara langsung terhadap harga jual tersebut.

2. Untuk mengetahui berapa besar pendapatan tirai terhadap pendapatan dan konsumsi keluarga petani jika dilihat dari sudut pandang waktu pemasaran di bulan-bulan biasa dibandingkan dengan bulan-bulan hari besar (lebaran, tahun baru). Maka menggunakan rumus sebagai berikut (Soekartawi, 2010)

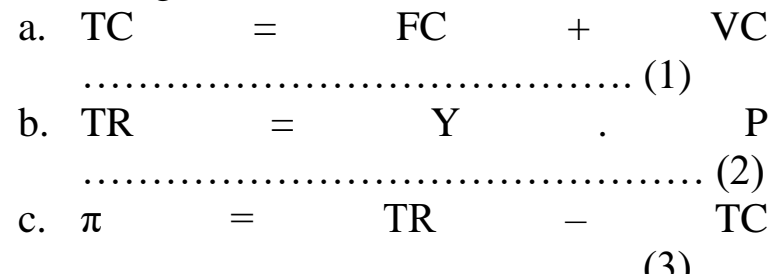

Keterangan :

TC : Total Cost / Biaya Total $(\mathrm{Rp} / \mathrm{P})$

FC : Fixed Cost / Biaya Tetap (Rp/P)

VC : Variabel Cost / Biaya Variabel $(\mathrm{Rp} / \mathrm{P})$ 
TR : Total Revenue / Total Penerimaan $(\mathrm{Rp} / \mathrm{P})$

Y : Yield / Jumlah Produksi (Lembar/P)

$\mathrm{P}$ : Price / Harga (RP/Lembar)

$\pi \quad$ : Pendapatan $(\mathrm{Rp} / \mathrm{P})$

3. Untuk mengetahui kontribusi kerajinan tirai terhadap pendapatan dan pemenuhan konsumsi keluarga petani di Desa Rantau Durian I Kecamatan Lempuing Jaya OKI, maka menggunakan rumus sebagai berikut (Nasution dan Barizi, 2004)

$$
\begin{aligned}
& K=\frac{\text { PUS }}{\text { PUS + PUL }} \times 100 \% \\
& K=\frac{\text { PUS }}{C} \quad X 100 \%
\end{aligned}
$$

Keterangan :

$\mathrm{K}$ : Kontribusi (\%)

Kecil ; 0\%-33,33\%

Sedang

:33,34\%-66,66\%

Besar : 66,67\%-

99,99\%

PUS : Pendapatan Sampingan (Rp/bln)

PUL : Pendapatan Usaha Lain

C ; Total Konsumsi (Rp/bln).

\section{PEMBAHASAN}

\section{A. Proses Produksi}

Dalam proses produksi tirai ada beberapa hal yang harus dipersiapkan yaitu mulai dari persiapan alat dan pencarian bahan baku sampai dengan menghasilkan sebuah tirai :

1. Persiapan Alat

Alat yang digunakan dalam proses pembuatan tirai meliputi : parang, alat pengayam, dan alat pemotong tirai. Umumnya untuk alat pemotong pengrajin tidak memiliki sendiri oleh karena itu pengrajin menggunakan dengan system upah untuk tenaga kerja pemotongan tirai.

2. Bahan Baku

Bahan baku utama yang digunakan dalam pembuatan tirai ialah pelepah sawit dan tali. Untuk bahan baku pelepah umumnya pengrajin mencari sendiri di perkebunan milik PT. Tania Selatan yang tidak jauh dari Desa Rantau Durian I, bahan baku pelepah yang siap dianyam ialah yang sudah berupa bilahan-bilahan umumnya dengan panjang 2 meter dan tali untuk menganyam \pm 24 meter yang dipotongpotong sepanjang 2 meter sebanyak 12 helai. a. Pencarian, Pengumpulan dan Pemotongan Pelepah

Pencarian pelepah biasanya dilakukan oleh satu orang yaitu tenaga kerja laki-laki setelah pulang dari menyadap karet. Lokasi pencarian pelepah adalah di perkebunan milik PT. Tania Selatan yang berada tidak jauh dari desa tersebut. Pencari pelepah sawit hanya mengumpulkan pelepah yang sudah tersedia diperkebunan tersebut tanpa mengambil dari batang kelapa sawit kemudian daun yang masih menempel dibersihkan dari pelepah dengan menggunakan golok, bila sudah bersih selanjutnya dilakukan pemotongan pelepah sesuai dengan ukuran yaitu sepanjang 2 meter.

b. Pembelahan dan Penjemuran Pelepah

Pembelahan dan penjemuran pelepah membutuhkan waktu \pm 3 jam yang dikerjakan di rumah oleh satu atau dua orang tenaga kerja. Rata-rata dalam satu pelepah dibelah menjadi 8 bilahan. Kemudian pelepah yang sudah dibelah tersebut dijemur dibawah terik matahari dan dibiarkan sampai kering selama \pm 2 hari hingga pelepah tersebut siap untuk dianyam. c. Pengayaman

Alat yang digunakan untuk penganyaman adalah terbuat dari bahan kayu, paku dan papan. Alat ini dibuat khusus oleh pengrajin sendiri guna memudahkan penganyaman. Biasanya penganyaman dikerjakan oleh tenaga kerja wanita dan membutuhkan waktu $\pm 3 \mathrm{jam} / \mathrm{pp}$ untuk satu orang penganyam guna untuk mendapatkan penghasilan tambahan bagi 
keluarganya. Proses penganyaman dimulai dengan mempersiapkan bahan dasar pelepah yang sudah menjadi bilahan-bilahan yang siap dianyam dan disusun di atas alat penganyam. Jumlah bilah pelepah kelapasawit yang digunakan untuk pembuatan tirai bervariasi tergantung dari lebar tirai yang akan dibuat. Lebar tirai yang dibuat adalah $\pm 2 \mathrm{M}^{2}$ dan membutuhkan bilahan pelepah kelapa sawit sebanyak 168 / tirai. Dalam satu buah pelepah sawit menghasilkan \pm 8 bilah bahan baku maka dalam pembuatan satu buah tirai pelepah kelapa sawit membutuhkan \pm 12 pelepah kelapa sawit. Kebutuhan tali pertirai adalah sebanyak 24 meter yang dipotong-potong sepanjang 2 meter sebanyak 12 helai dan dikaitkan pada alat penganyam kemudian digulung dengan potongan kayu yang sudah disiapkan lalu penganyaman bias dimulai.

d. Pemotongan Tirai

Alat pemotong tersebut dari parang/golok yang dibuat khusus yang memiliki pegangan yang menjulang ke atas guna memudahkan proses pemotongan tirai. Fungsi pemotongan tersebut ialah untuk merapikan setiap sisi kerajinan tirai. Umumnya pengrajin tidak memiliki alat ini, system yang digunakan oleh pengrajin adalah menyewa atau dengan member upah potong. Upah yang diberikan untuk pemotongan adalah sebesar Rp 250/tirai, maka rata-rata upah yang dikeluarkan pengrajin untuk tenaga kerja pemotongan adalah sebesar Rp 2.692,-/tirai/pp.

e. Penggulungan

Penggulungan tirai membutuhkan waktu \pm 5 menit perproses produksi yang dilakukan oleh tenaga kerja laki-laki dengan meletakkan lembaran tirai sebanyak 8 lembar di atas lantai lalu digulung secara manual, setelsh itu tirai yang sudah digulung diletakkan di atas dua kayu penjepit yang dibuat pengrajin untuk mempermudah pengikatan gulungan tirai supaya menjadi kuat dan tidak mudah lepas ketika proses pengangkutan.

\section{B. Marjin Harga pada Pemasaran Tirai di Tingkat Desa Rantau Durian I}

Pemasaran merupakan proses social dari individu ke kelompok untuk mendapatkan apa yang mereka butuhkan denganmenciptakan, menawarkan dan secara bebas mempertukarkan produk dan jasa. Pada proses pemasaran tirai, pengrajin kurang memperhatikan informasi pasar, sehingga pengrajin dalam menjual tirai mengalami kesulitan. Maka rata-rata pengrajin hanya menjual tirai yang mereka hasilkan ditingkat pengepul saja. Sedangkan untuk menentukan harga kerajianan tirai ditentukan oleh kesepakatan antara pengepul dan pengrajin itu sendiri, yaitu melalui tawar menawar sehingga terjadi transaksi jual beli dan terbentuklah harga. Karena penjualan tirai ke pengepul dalam jumlah banyak maka harga yang ditawarkan menjadi rendah bila dibandingkan ketika pengrajin menjual ke konsumen langsung. Harga jual yang ditawarkan di tingkat pengepul adalah sebesar Rp 15.000,-/tirai sedangkan harga ditingkat desa sebesar $\mathrm{Rp}$ 18.000,-/tirai, maka marjin harga yang diperoleh adalah sebesar $\mathrm{Rp} 3.000,-/$ tirai, namun pengrajin tidak menjual tirai ke konsumen dalam desa secara langsung karena minat konsumen pada kerajinan tirai setempat sangat terbatas sebab umunya masyarakat Desa Rantau Durian I adalah sebagai pengrajin tirai.

\section{Analisis Pendapatan Tirai pada Bulan-Bulan Hari Besar.}

1. Biaya Produksi

Berdasarkan hasil olahan data primer, diperoleh bahwa biaya variable meliputi : biaya sarana produksi dan biaya tenaga kerja. Biaya saprodi yaitu biaya yang dikeluarkan untuk pembelian tali kepada pengepul dengan harga sebesar $\mathrm{Rp}$ 90.000/tali, dan biaya yang dikeluarkan dalam satu kali proses produksi rata-rata adalah sebesar Rp 1.119,-/tirai. Sedangkan 
biaya yang dikeluarkan untuk satu lembar tirai rata-rata adalah sebesar $\mathrm{Rp} 1.762,-$. Biaya tenaga kerja yang dikeluarkan dalam pembuatan tirai meliputi : biaya tenaga kerja pengumpulan dan pemotongan pelepah, biaya pembelahan dan penjemuran pelepah, pengayaman, pemotongan tirai dan Tabel 1. Rata-rata biaya produksi pada kerajinan Tirai di Desa Rantau Durian I Kecamatan Lempuing Jaya OKI, 2015.

\begin{tabular}{cllr}
\hline No & \multicolumn{1}{c}{ Uraian } & \multicolumn{1}{c}{ Satuan } & Nilai \\
\hline 1. & Biaya Tetap & Rp/PP & $\mathbf{1 . 3 7 6}$ \\
& Penyusunan Alat & Rp/PP & 257 \\
& Pajak & Rp/PP & 1.119 \\
2. & Biaya Variabel & Rp/PP & $\mathbf{9 4 . 1 5 4}$ \\
& Biaya Saprodi & Rp/PP & 19.385 \\
& Biaya Tenaga Kerja & Rp/PP & 74.769 \\
3. & Total Biaya Produksi & Rp/PP & $\mathbf{9 5 . 5 3 0}$ \\
\hline
\end{tabular}

Sumber : Olahan Data Primer, 2015.

Berdasarkan table 1 di atas dapat diketahui bahwa dalam satu kali proses prosukai biaya total produksi yang dikeluarkan pada kerajinan tirai adalah sebesar Rp 95. 530,- dari penjumlahan biaya tetap sebesar Rp 1.376 ditambah dengan biaya variable sebesar Rp 94.154,--

2. Produksi, Penerimaan dan Pendapatan Jumlah produksi adalah jumlah yang dihasilkan oleh berbagai jenis factor-faktor Tabel 2. Rata-rata Produksi, Penerimaan dan Pendapatan pada kerajinan tirai di Desa Rantau Durian I Kecamatan Lempuing OKI, 2015.

\begin{tabular}{cllr}
\hline No & \multicolumn{1}{c}{ Uraian } & \multicolumn{1}{c}{ Satuan } & \multicolumn{1}{r}{ Nilai } \\
\hline 1. & Produksi & Lembar & 11 \\
2. & Harga Jual & Rp/lembar & 15.000 \\
3. & Penerimaan & Rp/PP & 165.000 \\
4. & Biaya Produksi & Rp/PP & 95.530 \\
5. & Pendapatan & Rp/PP & 66.008 \\
\hline
\end{tabular}

Sumber : Olahan Data Primer, 2015.

Berdasarkan tabel 2 di atas produksi tirai di Desa Rantau Durian I rata-rata perproses produksi membutuhkan \pm 7 ikat pelepah kelapa sawit yang akan menghasilkan 11 lembar tirai. Penerimaan diperoleh dari banyaknya produksi rata-rata yang dihasilkan yaitu 11 lembar dikalikan harga jual rata-rata per tirai $\mathrm{Rp} 15.000$,- maka rata- penggulungan maka biaya yang dikeluarkan dalam satu kali proses produksi rata-rata adalah sebesar Rp 74.769,-- maka total biaya variable yang dikeluarkan oleh pengrajin tirai perproses produksi sebesar Rp 94. 154. Berikut ini adalah rincian biaya produksi kerajinan tirai. 
produksi rata-rata $\mathrm{Rp} 66.008,-$. $\quad$ Karena biaya yang dikeluarkan termasuk tenaga kerja, sementara umumnya pengrajin menggunakan tenaga kerja keluarga sehingga tanpa menghitung biaya tenaga kerja maka rata-rata pendapatan yang diperoleh dari kerajinan tirai adalah sebesar Tabel 3. Produksi Tirai Perbulan Tahun 2015.

\begin{tabular}{lcr}
\hline \multicolumn{1}{c}{ Bulan } & Produksi & Pendapatan \\
\hline Januari & 149 & 1.003 .380 \\
Februari & 150 & 678.392 \\
Maret & 166 & 768.271 \\
April & 166 & 812.978 \\
Mei & 161 & 834.071 \\
Juni & 150 & 918.888 \\
Juli & 175 & 1.052 .432 \\
Agustus & 176 & 1.124 .791 \\
September & 165 & 1.064588 \\
Oktober & 161 & 1.034 .829 \\
November & 142 & 1.033 .745 \\
Desember & 148 & 1.121 .397 \\
\hline Jumlah & 1.918 & 11.447 .762 \\
Rata-rata & 160 & 953.980 \\
\hline
\end{tabular}

Sumber : Olahan Data Primer, 2015.

Dari data di atas, pada Bulan Januari hingga Bulan Juni produksi tirai mengalami naik turun, seperti pada Bulan Januari yaitu produksi rendah karena kurangnya ketersediaan bahan baku dan tenaga kerja, sebab banyak tenaga kerja atau pengrajin tirai yang ikut merayakan tahun baru dengan liburan ke tempat saudara. Sedangkan pada Bulan Februari hingga Bulan Juni permintaan tirai berkurang sehingga menyebabkan produksi dan harga jual tirai menjadi rendah. Peningkatan produksi dan pendapatan tirai terjadi pada Bulan Juli sampai Bulan September, dan produksi tertinggi terjadi pada Bulan Agustus yaitu sebesar 176 tirai dengan pendapatan sebesar Rp 1.124.791. Hal ini karena sumber tenaga kerja tersedia dan permintaan tirai meningkat serta diikuti dengan kenaikan harga jual kerajinan tirai, sehingga pendapatan pengrajin tirai meningkat. Sedangkan produksi tirai pada Bulan
Rp 140.778,-/pp. Disamping itu karena kegiatan satu sama lain saling berkaitan, jika kegiatan utama sebagai petani karet/petani padi sudah selesai selebihnya kerajinan tirai dapat dilakukan setiap hari sehingga pendapatan perproses Rp 140.778,- menjadi pendapatan per hari. 
lain yaitu Bulan Februari hingga Bulan Juni perubahan jumlah produksi dari suplai tirai serta penerimaan diyakini telah disebabkan oleh harga ditingkat pengepul turun sehingga tenaga kerja lebih memilih dengan kegiatan lainnya (buruh), sehingga pendapatan yang diperoleh dari usaha tirai juga menurun, namun total pendapatan keluarga tidak karena diimbangi dengan kegiatan lainnya.

\section{Kontribusi Kerajinan Tirai}

Kontribusi pendapatan adalah sumbangan pendapatan dari usaha tirai terhadap total pendapatan keluarga. Sedangkan kontribusi terhadap pemenuhan konsumsi keluarga adalah sumbangan pendapatan usaha tirai terhadap pemenuhan konsumsi pangan dan non pangan keluarga petani di Desa Rantau Durian I Lempuing Jaya Ogan Komering Ilir.

Tabel 4. Kontribusi Kerajinan Tirai terhadap Pendapatan dan Konsumsi Keluarga Petani di Desa Rantau Durian I Lempuing Jaya Ogan Komering Ilir.

\begin{tabular}{|c|c|c|c|}
\hline No & Uraian & Satuan & Nilai \\
\hline 1. & Pendapatan Tirai & $\mathrm{Rp} / \mathrm{B} \ln$ & 1.192 .664 \\
\hline 2. & Pendapatan Padi & $\mathrm{Rp} / \mathrm{B} \ln$ & 657.692 \\
\hline 3. & Pendapatan Karet & $\mathrm{Rp} / \mathrm{B} \ln$ & 2.692 .308 \\
\hline 4. & Buruh & $\mathrm{Rp} / \mathrm{B} \ln$ & 119.658 \\
\hline 5. & Warung Manisan & $\mathrm{Rp} / \mathrm{B} \ln$ & 197.436 \\
\hline 6. & Total Pendapatan Keluarga & $\mathrm{Rp} / \mathrm{B} \ln$ & 4.859 .758 \\
\hline 7. & Konsumsi & $\mathrm{Rp} / \mathrm{B} \ln$ & 3.183 .653 \\
\hline 8. & Kontribusi Tirai terhadap Total Pendapatan & $\%$ & 24 \\
\hline 9. & Keluarga & $\%$ & 40 \\
\hline & $\begin{array}{l}\text { Kontribusi Tirai terhadap Pemenuhan Konsumsi } \\
\text { Keluarga }\end{array}$ & & \\
\hline
\end{tabular}

Sumber : Olahan Data Primer, 2015.

Berdasarkan table di atas maka kontribusi pendapatan tirai terhadap total pendapatan keluarga atau sumbangan yang diberikan dari pendapatan tirai terhadap total pendapatan keluarga adalah sebesar $24 \%$. Kontribusi tirai terhadap pendapatan keluarga adalah hasil dari rata-rata pendapatan tirai sebesar Rp 1.192.664,/bulan yang dibagi dengan total pendapatan keluarga sebesar Rp 4.859.758,-/bulan yang dikalikan $100 \%$. Sedangkan kontribusi tirai terhadap pemenuhan konsumsi keluarga petani adalah sebesar $40 \%$, yaitu hasil dari rata-rata pendapatan tirai sebesar $\mathrm{Rp}$ 1.192.664,-/bulan yang dibagi dengan ratarata kebutuhan konsumsi keluarga perbulan sebesar Rp 3.183.653,-/bulan dan dikali $100 \%$.

\section{Kesimpulan}

1. Marjin pemasaran pada penjualan eceran dan partai besar berbeda. Dimana

penjualan eceran atau petani menjual langsung ke konsumen adalah $\mathrm{Rp}$ 18.000,-. Sedangkan petani menjual ke partai besar dengan volume banyak adalah Rp 15.000,-, maka marjin pemasaran adalah sebesar Rp 3.000,-.

2. Penerimaan yang diperoleh pengrajin tirai di Desa Rantau Durian I rata-rata sebesar Rp 165.000,-/pp.

3. Pendapatan pada bulan-bulan biasa lebih kecil dari bulan-bulan hari besar.

4. Kontribusi kerajinan tirai terhadap pendapatan keluarga petani di Desa Rantau Durian I yaitu sebesar $24 \%$. Sedangkan kontribusi tirai terhadap konsumsi keluarga petani di Desa Rantau Durian I yaitu sebesar $40 \%$.

\section{DAFTAR PUSTAKA}

Anonim. 2009. http:// faizulmubarak. Wordpress.com/2009/11/04/bab-iv- 
struktur-ongkos-penerimaan-dan-pasar. Diakses pada tanggal 6 april 20015

Anonim 2010. Direktori industry pengolahan(Manufakturing industry directory) Indonesia. Badan pusat statistik. Jakarta diakses pada tanggal 7 april 2015

Anonim.2011. Sumatra Selatan dalam rangka. Dinas Perkebunan Sumatra Selatan. Dinas Perkebunan Sumatra Selatan. Palembang

Anonim. 2008. http://www.sjdih.depkeu.go.id/fulltext/2 008/20tahun2008UU.htm diakses tanggal 25 juli 2015 pukul 20.36 .

Azziziano, R.W. 2005. Pengantar Tataniaga Pertanian: Diklat Kuliah. Universitas Lampung

Dany H. 2006. Kampus Ilmiah Populer, Gita Media Press. Surabaya

Faperta. 2011. Analisis Usaha Tani. Mikolehi.Files.Wordpress.com/2009/06/ analisis-usahatani.ppt. Diakses pada tanggal 7 April 2015

Fauzi, Y. Widyastuti Yustina, E. Satyawibawa Iman dan Paeru, R. 2012. Kelapa Sawit. Penebar Swadaya. Jakarta

Firdaus m.2009. manajemen agribisnis. Ikrar mandiri Abadi Jakarta

Galih. 2010. Analisis Pembuatan Tirai di Desa Rantau Durian Kecamatan Lempuing Jaya Kabupaten Ogan Komering Ilir. Praktik Lapangan. STIPER Belitang. (Tidak dipublikasikan)

Haryati.1992. M anajemen Produksi. Lembaga Penerbit Fakultas Ekonomi Universitas Indonesia. Jakarta

Kotler,P.2002. Manajemen Pemasaran. Prenhallindo. Jakarta

Limbong dan Sitorus.2009. Pengantar Tataniaga Pertanian Jurusan Ilmu sosial Ekonomi Pertanian. IPB

Pendekatan Praktis dan Aplikatif. Bandung: PT Refika Aditama
Mulyadi.2009. Sistem Akuntansi. Baldad Grafiti Press. Palembang

Nesoetion, A.H. dan Barizi.2004. Metode Statistik Non Prametrik.PT. Gramedia Jakarta

Ricky, Ronal dan Ebert. 2006. Bisnis Akuntansi Manajemen, Erlangga. Jakarta

Saifuddin,AM. 2005. Pemasaran Produksi Pertanian dan Pengkajian Pemasaran Komoditas. Bogor.IPB

Sastrosayono. 2003. Budidaya Kelapa Sawit. Agromedia Pustaka. Purwokerto Sjarkow,F.2010. Manajemen Agrabisnis. Palembang: CV Baldad Grafiti Press. Palembang

Sukirno,S. 2010. Modul Prosedur Pembelian Barang Penjualan dan Sistem Persediaan. PT Intan Pariwara, Jakarta 2012. Mikro Ekonomi Teori Pengantar.PT Raja Grafindo Persada. Jakarta

Supriyanti. 2012. Analisis Kelayakan Usaha Cincau Hitam (permna oblongifolia) di Desa Tanah Merah Kecamatan Belitang Madang Raya Kabupaten Ogan Komering Ulu Timur Skripsi. STIPER Belitang. (Tidak dipublikasikan)

Teken dan Asnawi.2007. Faktor-Faktor Produksi Gramedia. Jakarta

Wardoyo. 2014. Analisis Nilai Tambah dan Kontribusi Kacang Sangrai Dalam Memenuhi Konsumsi Rumah Tangga di Desa karangsari Kecamatan Belitang III Kabupaten OKU Timur. Skripsi. STIPER Belitan. (Tidak dipublikasikan)

Yulandi. 2014. Nilai Tambah Pengolahan Ubi Kayu (Manihot utilisma) Menjadi Beras OSIN di Desa Sukarami Kecamatan Belitang Kabupaten OKU Timur. Skripsi. STIPER Belitang (Tidak dipublikasikan) 